\title{
Larval morphology of some Anisopliini grain beetles with a key to their larvae (Coleoptera: Scarabaeoidea: Rutelidae: Anomalinae)
}

\author{
Estefanía MICÓ, José R. VERDÚ and Eduardo GALANTE \\ Centro Iberoamericano de la Biodiversidad (CIBIO), Universidad de Alicante, 03080-Alicante, Spain
}

Key words. Scarabaeoidea, Rutelidae, Anomalinae, Anisopliini, Anisoplia, larvae, morphology, description, taxonomy, key

\begin{abstract}
The third instar larvae of three Anisoplia species, Anisoplia baetica Erichson, 1847, Anisoplia depressa Erichson, 1847 and Anisoplia remota Reitter, 1889 are described and illustrated to show the diagnostic characters of the species. The third instar larva of the monospecific genus Anthoplia, represented by Anthoplia floricola (F., 1787) is also described and illustrated. These four species are included in a revised key to the larvae of Anisopliini, which now includes four genera, and ten species. The taxonomic status of Anthoplia based on the larval morphology, is discussed.
\end{abstract}

\section{INTRODUCTION}

The tribe Anisopliini includes a total of five genera in the Paleartic Region (Baraud, 1986): Chaetopteroplia Medvedev, 1949, Hemichaetoplia Baraud, 1986, Brancoplia Baraud, 1986, Anthoplia Medvedev, 1949, and Anisoplia Schönherr, 1817. The first three genera comprise a total of 20 species showing a circummediterranean distribution except for the Iberian peninsula. The monospecific genus Anthoplia is known from North Africa (Morocco, Algeria, Tunisia and Libya) and from almost all of the Iberian Peninsula except the Northwest (Baraud, 1992). The genus Anisoplia is the most abundant and the most widely spread genus of Anisopliini; with over 50 species, this Eurasian genus does not extend further north than the line joining Paris-Berlin-Moscow (Machatschke, 1961).

Adults of Anisopliini feed exclusively on grass pollen, whereas the larvae are polyphagous and feed on the roots of many plants. Although the larvae of many Anisopliini species have been considered as pests of several crops (Bogachev, 1946), little is known about the larval morphology, or adult and larval biology of the tribe. Medvedev (1949) illustrated dorsal and ventral views of the last abdominal segment of Chaetopteroplia segetum (Herbst, 1783), Anisoplia (Autanisoplia) austriaca (Herbst, 1783), and Anisoplia (Anisoplia) deserticola Fischer, 1824. Few years later, Medvedev (1952) improved on the descriptions of these species and described the larvae of Brancoplia leucaspis (Castelnau, 1840), Anisoplia (Anisoplia) alazanica Zaitzev, 1918 and Anisoplia (Anisoplia) farraria Erichson, 1847, and provided a key to the species of Anisoplia. However, he could not separate $A$. alazanica from $A$. farraria. In the short description he gave of $A$. farraria he emphasized the similarity between $A$. farraria and $A$. alazanica, and did not illustrate the first species. Zacharieva-Stoilova (1962) contributed to the knowledge of Anisopliini larvae by describing and illustrating the last abdominal segment (ventral and dorsal view) and the head of Anisoplia (Anisoplia) lata Erichson, 1847 and Anisoplia (Anisoplia) agricola (Poda, 1761). However, none of these contributions constituted a detailed description and no more new descriptions have been published.

Studies of larvae suggested that larval mophology could be very useful in the systematic analysis of the Scarabaeoidea (Ritcher, 1966; Edmonds \& Halffter, 1978; Verdú et al., 1998)

In this study, we describe the third larval instar of Anisoplia (Anisoplia) baetica Erichson, 1847, Anisoplia (Anisoplia) depressa Erichson, 1847, Anisoplia (Anisoplia) remota Reitter, 1889 and Anthoplia floricola (F., 1787). These species are included in a revised key to the larvae of Anisopliini.

\section{MATERIAL AND METHODS}

A total of 10 to 20 adult specimens of each species were kept in plastic breeding cages $(20 \mathrm{~cm}$ high, $15 \mathrm{~cm}$ wide) with soil and grass. The lid was an opening ( $6 \mathrm{~cm}$ in diameter) covered with a gauze screen. These breeding cages were maintained in an environmental chamber at $25^{\circ} \mathrm{C}: 20^{\circ} \mathrm{C}(\mathrm{L}: \mathrm{D}), 80 \pm 5 \% \mathrm{RH}$, and a photoperiod of $15 \mathrm{~L}$ : 9D. The breeding cages were examined weekly and the results recorded.

The different larval instars of each species were fixed in KAAD solution (Carne, 1951) for $24 \mathrm{~h}$ and preserved in $70 \%$ ethanol. Specimens are deposited in the Collection of Entomology of the University of Alicante, Spain (CEUA). In the description of larvae the anatomical designations of Ritcher (1966) were used. The median of some characters is presented in brackets.

\section{RESULTS}

\section{Common morphological characteristics of the third instar larvae of Anisopliini.}

Body. Total length 25-28 mm. Body C-shaped, arched at the level of 4th abdominal segment (Figs 1, 14).

Head. Maximum width of head capsule $2.8 \mathrm{~mm}$ (Figs $2,15,27,38)$. Cranium. Colour light yellowish. Frons $(F)$ sparsely punctate, with 4-8 posterior frontal seta $(P F S), 1$ anterior angle seta $(A A)$ and 1 exterior frontal seta $(E F S)$ on each side. Dorsoepicranium with 4-8 small to medium setae $(D E S)$ in a line diverging from center-base of head; 

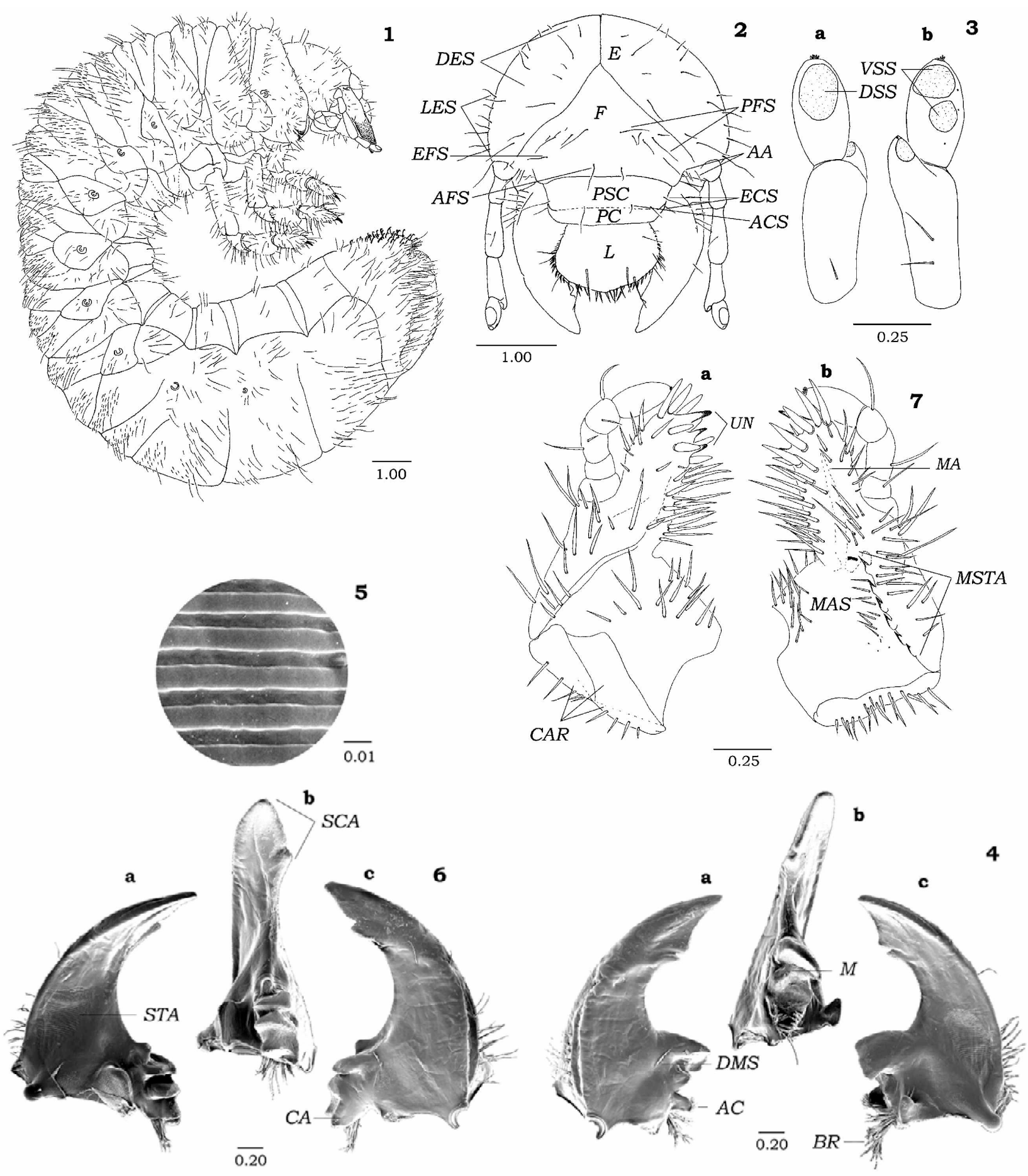

Figs 1-7: Anthoplia floricola third-instar larva. 1- habitus; 2 - frontal view of head ( $E$ - epicranium, $D E S$ - dorsoepicraneal setae, $L E S$ - lateral external setae. $F$ - frons, $P F S$ - posterior frontal setae, $E F S$ - exterior frontal setae, $A F S$ - anterior frontal setae. $E C S$ exterior clypeal setae. $A C S$ - anterior clypeal setae, $P C$ - preclypeus, $P C S$ - postclypeus, $L$ - labrum); 3 - dorsal (a) and ventral (b) view of apical antennal segment showing sensory spots (DSS - dorsal sensory spots, VSS - ventral sensory spots); 4 - dorsal view (a), lateral view (b) and ventral view (c) of left mandible ( $D M S$ - dorso molar setae, $M$ - molar area, $A C$ - acia, $B R-$ brustia); 5 stridulatory area of mandible; 6 - dorsal view (a), lateral view (b) and ventral view (c) of right mandible (STA - stridulatory area, $S C A$ - scissorial area, $C A$ - calx); 7 - ventral (a) and dorsal (b) view of maxilla (MA - mala, UN - unci, MSTA - maxillary stridulatory area, $M A S$ - maxillary articulating area, $C A R-$ cardo).

11-16 medium to long lateral setae (LES). Clypeus. Shape trapezoidal, with 2 anterior clypeal setae and 2 external clypeal setae on each lateral edge of postclypeus $(P S C)$; preclypeus $(P C)$ weakly sclerotized. Labrum $(L)$ asymmetrical; longer and narrower than clypeus, sparsely punctate and with 2-3 posterior setae near the base, 2 anterior setae near the apex and 4 stout setae at apex flanked by a prominent, pointed seta. Epipharynx. Pleg- 

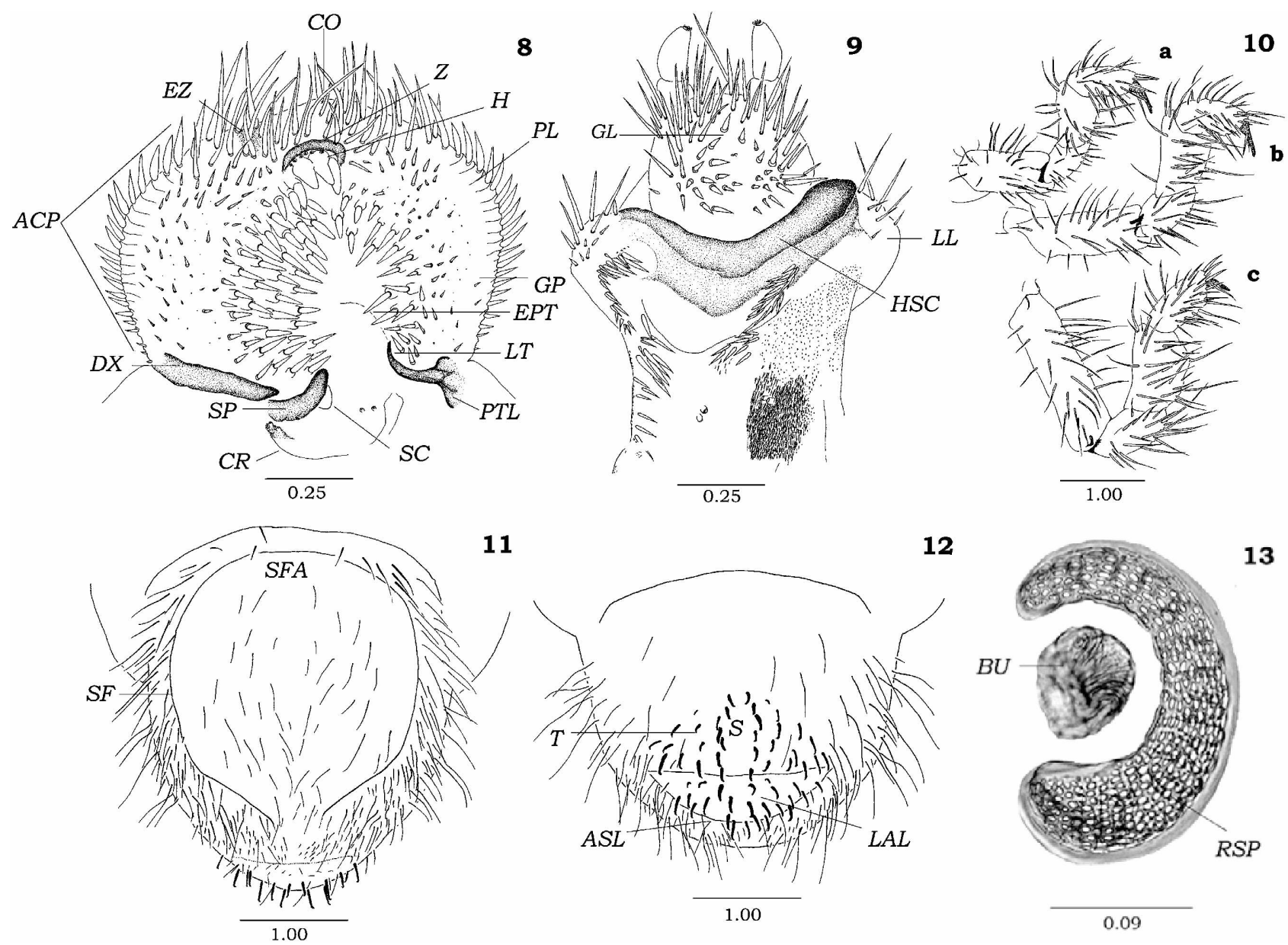

11

12

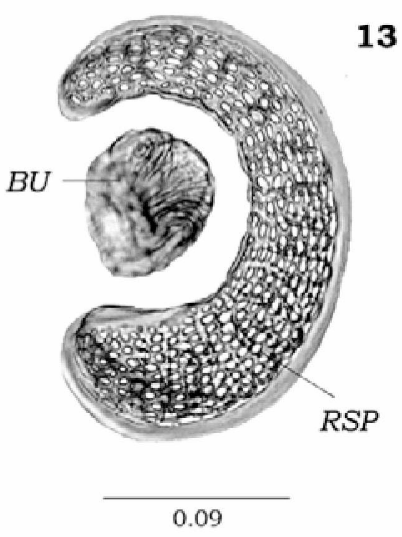

Figs 8-13: Anthoplia floricola third-instar larva. 8 - epipharynx ( $H$ - haptomerum, $Z$ - zygum, $E Z$ - epizygum, $C O$ - corypha, $A C P$ - acanthoparia, $P L$ - plegmatium, $G P$ - gymnoparia, $D X$ - dexiotorma, $L T$ - laetorma, $P T L$ - pternotorma, $E P T$ - epitorma, $S P$ - sclerotized plate, $S C$ - sensorial cone, $C R$ - crepis); 9 - hypopharynx ( $G L$ - glossa, $L L$ - lateral lobes, HSC - hypopharingeal sclerome); 10 - legs - prothoracic (a), mesothoracic (b), metathoracic (c); 11 - dorsum of last abdominal segment (SF - subcircular furrow, $S F A$ - subcircular furrow area); 12 - venter of last abdominal segment ( $T$ - tegilla, $S$ - septula, $A S L$ - anal slit, $L A L$ - lower anal lobe); 13 - prothoracic spiracle ( $R S P$ - respiratory plate, BU - bulla).

matium (PL) composed of 10-19 plegmata. Corypha $(C O)$ with 2 stout setae flanked by a sensillum on each side. Epizygum (EZ) present. Haptomerum $(H M)$ consisting of a curved, sclerotized zygum $(Z)$ with about 10 sensilla, and 3 prominent, backward projecting heli $(H)$. Acanthoparia $(A C P)$ with about 20 flattened setae, sickleshaped and decreasing in size posteriorly. Chaetoparia $(C H P)$ well-developed, covered with longitudinal rows (4 on the right and 2-3 on the left) of long, stout setae and many smaller and finer setae near the gymnoparia $(G P)$. Epitorma $(E P T)$ slightly apparent, dividing pedium. Laeotorma $(L T)$ with pternotorma $(P T L)$ present. Dexiotorma $(D X)$ slightly sinuated, broadest at base; pternotorma absent. Haptolachus $(H L)$ complete: crepis $(C R)$ lightly sclerotized in the form of a transverse bar expanded laterally with 2 sensilla on the right. Both nesia (sclerotized plate $(S P)$ and sensorial cone $(S C)$ ) present. Center of haptolachus with 2 sensilla. Mandibles (Figs 4, $6,17,19,30,32,41,43)$. Asymmetrical, with 2 scissorial teeth anterior to scissorial notch and 1 tooth posterior to notch. Ventral surface bearing a large, ovate stridulatory area $(S T A)$. Dorsal surface with 1 seta near the proximal end of the scissorial area and 1-2 dorsomolar setae. Left mandible with molar area $(M)$ bilobed. Basomedian angle with brustia $(B R)$ of setae. Acia $(A C)$ present. Molar area of right mandible consisting of 4 lobes. Calx $(C A)$ bearing a brustia of long setae. Maxilla (Figs 7, 20, 29, 40). Galea and lacinia fused, forming mala $(M A)$. Mala with large uncus at apex and 2 subterminal unci $(U N)$ fused at base and equal in size; surface with 3-4 indistinct rows of setae. Unci of mala surrounded by a circle of 8 stout setae. Cardo with $12-16$ setae. Stridulatory area (MSTA) with a row of apically pointing stridulatory teeth and a distal, blunt tubercle. Labium. Glossa $(G L)$ covered posteriorly with about 40 stout setae and distally with many, slender setae. Hypopharyngeal sclerome (HSC) asymmetrical; produced on right side into a strong, truncate process. Both lateral lobes $(L L)$ with $8-18$ setae arranged in 2-3 rows. Antenna. 4-segmented. First segment about half as long as second segment. Apical segment fusiform, bearing 1 dorsal $(D S S)$ and 2 ventral sensory spots $(V S S)$. 

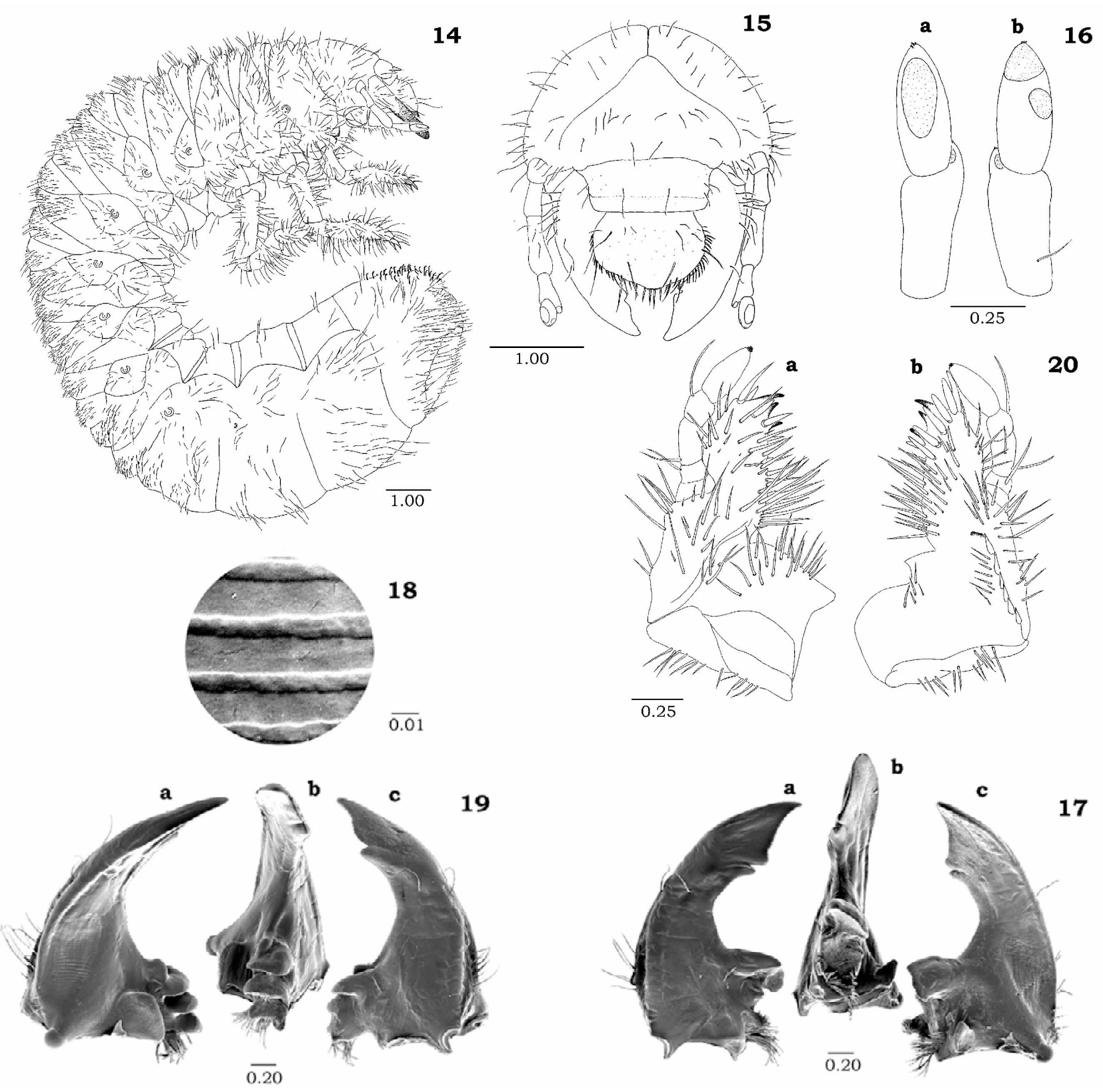

Figs 14-20: Anisoplia baetica third-instar larva. 14 - habitus; 15 - frontal view of head; 16 - dorsal (a) and ventral (b) view of apical antennal segment showing sensory spots; 17 - dorsal view (a), lateral view (b) and ventral view (c) of left mandible; 18 stridulatory area of mandible; 19 - dorsal view (a), lateral view (b) and ventral view (c) of right mandible; 20 - ventral (a) and dorsal (b) view of maxilla.

Thorax. Thoracic spiracles with C-shaped respiratory plate (Figs 13, 26, 35, 46). Legs (Figs 10, 23). Prothoracic legs (a) shorter than the mesothoracic (b) and metathoracic (c) pair. Claws slightly curved, bearing 2 setae at base. Claws of prothoracic and mesothoracic legs equal in length, those of metathorax half as long.

Abdomen. Dorsa of abdominal segments I-VII with 3-5 rows of short setae, each posterior row bearing long setae. Abdominal segments VIII-IX with sparse, medium to long setae. Spiracular area of abdominal segments with 16-23 short to medium setae. The spiracles of the abdominal segments II-VII similar in size, those of I and VIII conspicuously smaller (Figs 1,14). Pleural lobes of abdominal segments with 10-22 long setae. Dorsum of the last abdominal segment (Figs 11, 24, 36, 47) with subcircular furrow $(S F)$ present. Tegilla $(T)$ composed of 11-21 hamate setae. Anal slit $(A S)$ transverse, arcuate. Lower anal lip ( $L A L)$ possessing 21-28 hamate setae.

\section{Anthoplia floricola (F., 1787) third instar larva.}

Head. Mandibles. Stridulatory area consisting of many transverse ridges (Fig. 5); inter-ridge area 1.6 times the ridge width at centre. Maxilla (Fig. 7b). Stridulatory area with row of 5-7 (5) acute teeth and distal truncate process. Maxillary articulating area $(M A S)$ with a row of 7-13 (8) setae just parallel to stridulatory teeth.

Thorax. Size of prothoracic spiracles $0.21 \mathrm{~mm}$ high and $0.15 \mathrm{~mm}$ wide (Fig. 13); respiratory plate with infe- 

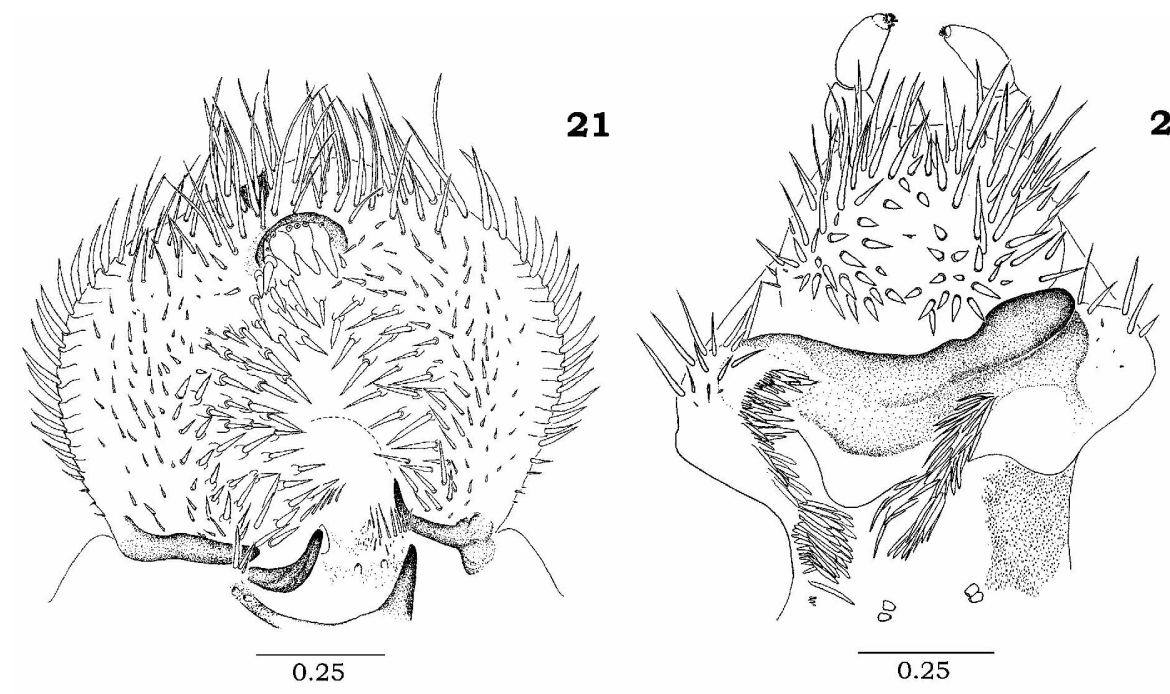

22

23

24

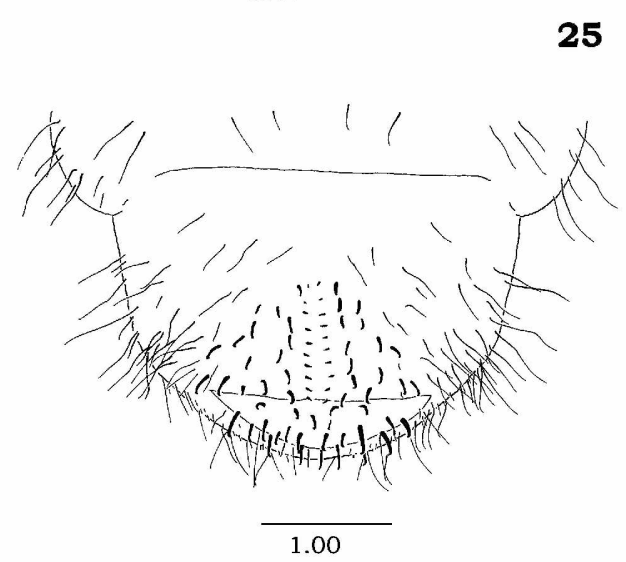

25
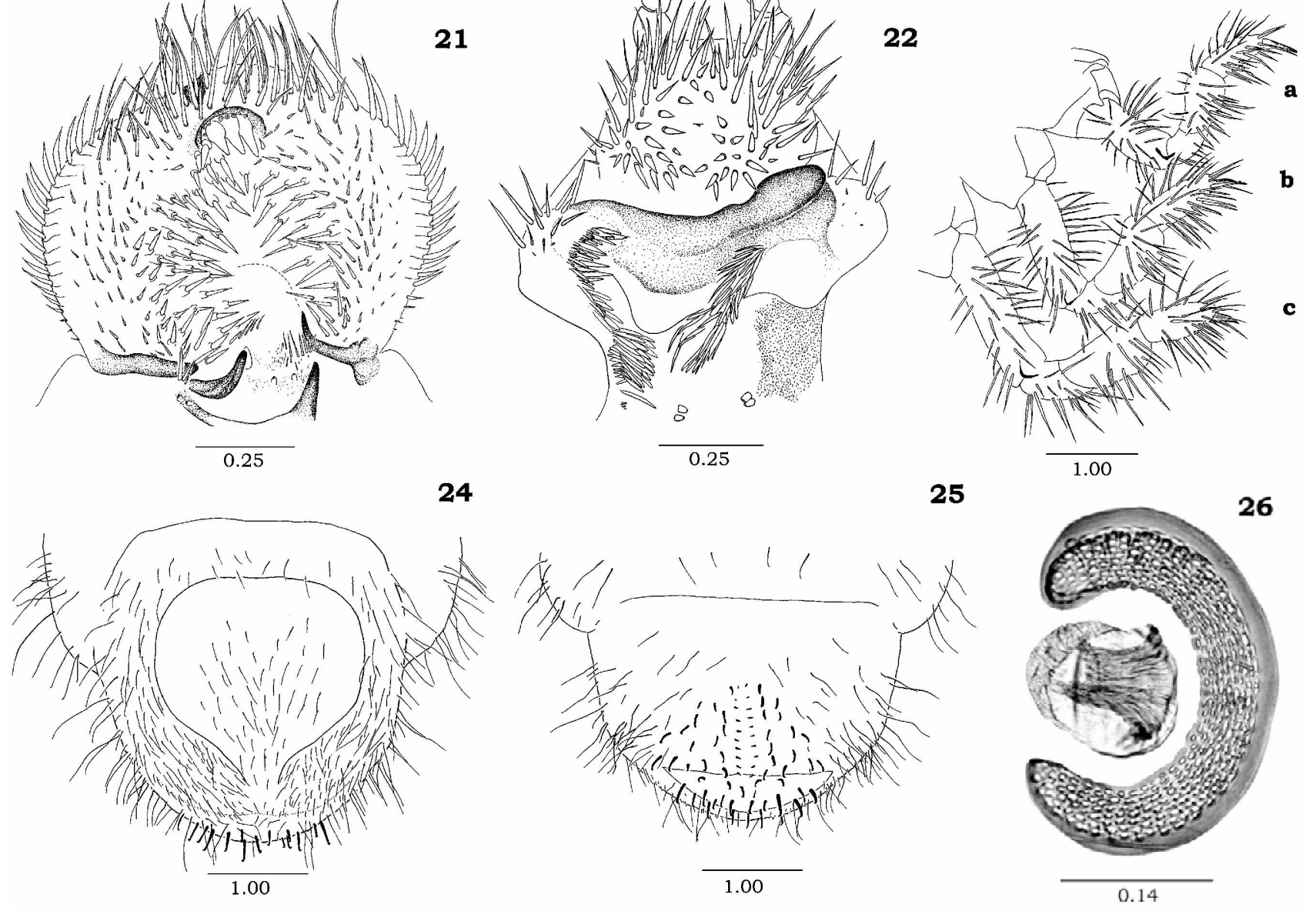

Figs 21-26: Anisoplia baetica third-instar larva. 21 - epipharynx; 22 - hypopharynx; 23 - legs - prothoracic (a), mesothoracic (b), metathoracic (c); 24 - dorsum of last abdominal segment; 25 - venter of last abdominal segment; 26 - prothoracic spiracle.

rior lobe conspicuously larger than superior lobe and with 8 holes across diameter at middle; holes suboval.

Abdomen. Raster without palidium (Fig. 12); Septula defined and elongated. Area defined by the subcircular furrow of dorsum of tenth abdominal segment being about $56 \%$ of the dorsal surface of the segment. Vestiture of the $S F A$ with isolated short and long setae, usually absent from lateral margins (Fig. 11).

Material studied. Description based on 20 third instar larvae reared from eggs laid by adults collected at Arenales del Sol, Alicante (Spain), V-1997, Micó \& Verdú leg.; La Mata, Torrevieja, Alicante (Spain), V-1996, Micó \& Verdú leg.; Villena, Alicante, V-1996, Micó leg.

\section{Anisoplia baetica Erichson, 1847 third instar larva.}

Head. Mandibles. Stridulatory area consisting of many transverse ridges (Fig. 18); inter-ridge area 2.1 times the ridge width at centre. Maxilla (Fig. 20b). Stridulatory area with row of 5-7 (6) acute teeth and distal truncate process. Maxillary articulating area with a row of 8-13 (9) setae just parallel to stridulatory teeth.

Thorax. Size of prothoracic spiracles $0.28 \mathrm{~mm}$ high and $0.21 \mathrm{~mm}$ wide (Fig. 26); Lobes of respiratory plate equal; distance between both lobes as wide as diameter of spiracle or slightly narrower; respiratory plate with 8 holes across diameter at middle; holes suboval.

Abdomen. Raster with palidium possessing two parallel rows of 6-10 (8) pali (Fig. 25). Area defined by the subcircular furrow of the dorsum of tenth abdominal segment about $43 \%$ of the dorsal surface of the segment. Vestiture of the $S F A$ with setae equal in length on centre and apex, absent from lateral and basal margins (Fig. 24).

Material studied. Description based on 12 third instar larvae reared from eggs laid by adults collected at Huélamos, Teruel (Spain), VII-1997, Micó \& Galante leg.; Embalse de Celemín, Cadiz (Spain), V-1997, Micó \& Verdú leg.

\section{Anisoplia remota Reitter, 1889 third instar larva.}

Head. Mandibles. Stridulatory area consisting of many transverse ridges (Fig. 31); inter-ridge area 4 times the ridge width at centre. Maxilla (Fig. 29b). Stridulatory area with row of 5-7 (6) acute teeth and distal truncate process. Maxillary articulating area with a row of 11-23 (16) setae just parallel to stridulatory teeth.

Thorax. Size of prothoracic spiracles $0.24 \mathrm{~mm}$ high and $0.18 \mathrm{~mm}$ wide (Fig. 35); Lobes of respiratory plate equal; distance between both lobes less than diameter of 

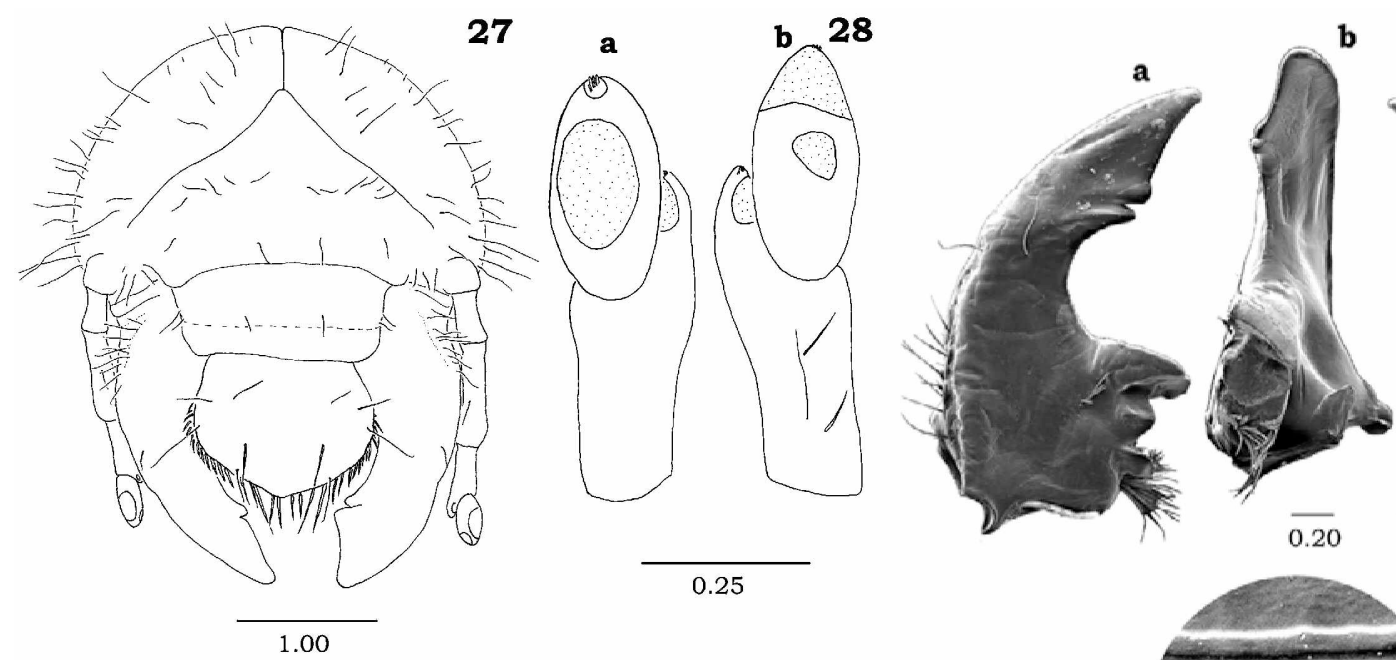

30
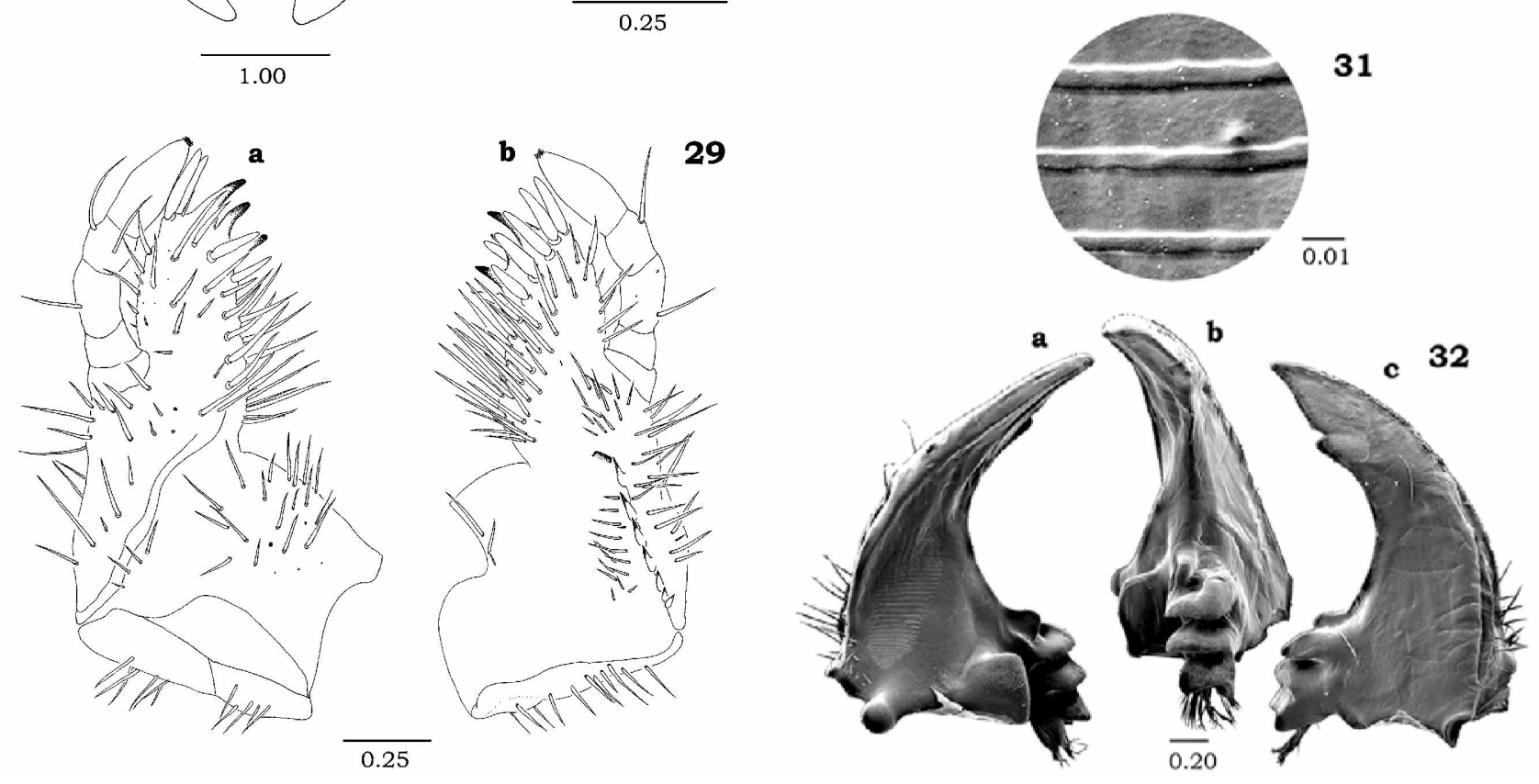

Figs 27-32: Anisoplia remota third-instar larva. 27 - frontal view of head; 28 - dorsal (a) and ventral (b) view of apical antennal segment showing sensory spots; 29 - ventral (a) and dorsal (b) view of maxilla; 30 - dorsal view (a), lateral view (b) and ventral view (c) of left mandible; 31- stridulatory area of mandible; 32 - dorsal view (a), lateral view (b) and ventral view (c) of right mandible.

the spiracle at the middle; respiratory plate with 8 holes across diameter at middle; holes suboval.

Abdomen. Raster possessing two parallel rows of 6-8 (7) pali (Fig. 37). Area defined by the subcircular furrow of the dorsum of tenth abdominal segment $45 \%$ of the dorsal surface of the segment. Vestiture of the SFA with setae equal in length on centre and apex, absent from lateral and basal margins (Fig. 36).

Material studied. Description based on 30 third instar larvae reared from eggs laid by adults collected at Arenales del Sol, Alicante (Spain), V-1997, Micó \& Verdú leg.; Embalse de Ulldecona, Castellón (Spain), VI-1997, Micó \& Verdú leg.; Villar de Olalla, Cuenca (Spain), VII-1997, Micó \& Galante leg.

\section{Anisoplia depressa Erichson, 1847 third instar larva.}

Head. Mandibles. Stridulatory area consisting of many transverse ridges (Fig. 42); inter-ridge area 2.5 times the ridge width at centre. Maxilla (Fig. 40b). Stridulatory area with row of 5-7 (6) acute teeth and distal truncate process. Maxillary articulating area with a row of 8-14 (12) setae just parallel to stridulatory teeth.

Thorax. Size of prothoracic spiracles $0.25 \mathrm{~mm}$ high and $0.17 \mathrm{~mm}$ wide (Fig. 46); Lobes of respiratory plate equal; distance between both lobes wider than the diameter of spiracle at middle; respiratory plate with 6 holes across diameter at middle; holes suboval.

Abdomen. Raster without palidium (Fig. 48); Septula defined and elongated. Area defined by the subcircular furrow of the dorsum of tenth abdominal segment $56 \%$ of the dorsal surface of the segment. Vestiture of the $S F A$ with short and long setae on centre and apex, absent from lateral and basal margins (Fig. 47).

Material studied Description based on 12 third instar larvae reared from eggs laid by adults collected at Prioro, León (Spain), VII-1999, Micó \& Verdú leg.; Rivera de la Granja, Salamanca (Spain), VII-1998, Micó \& Galante leg. 

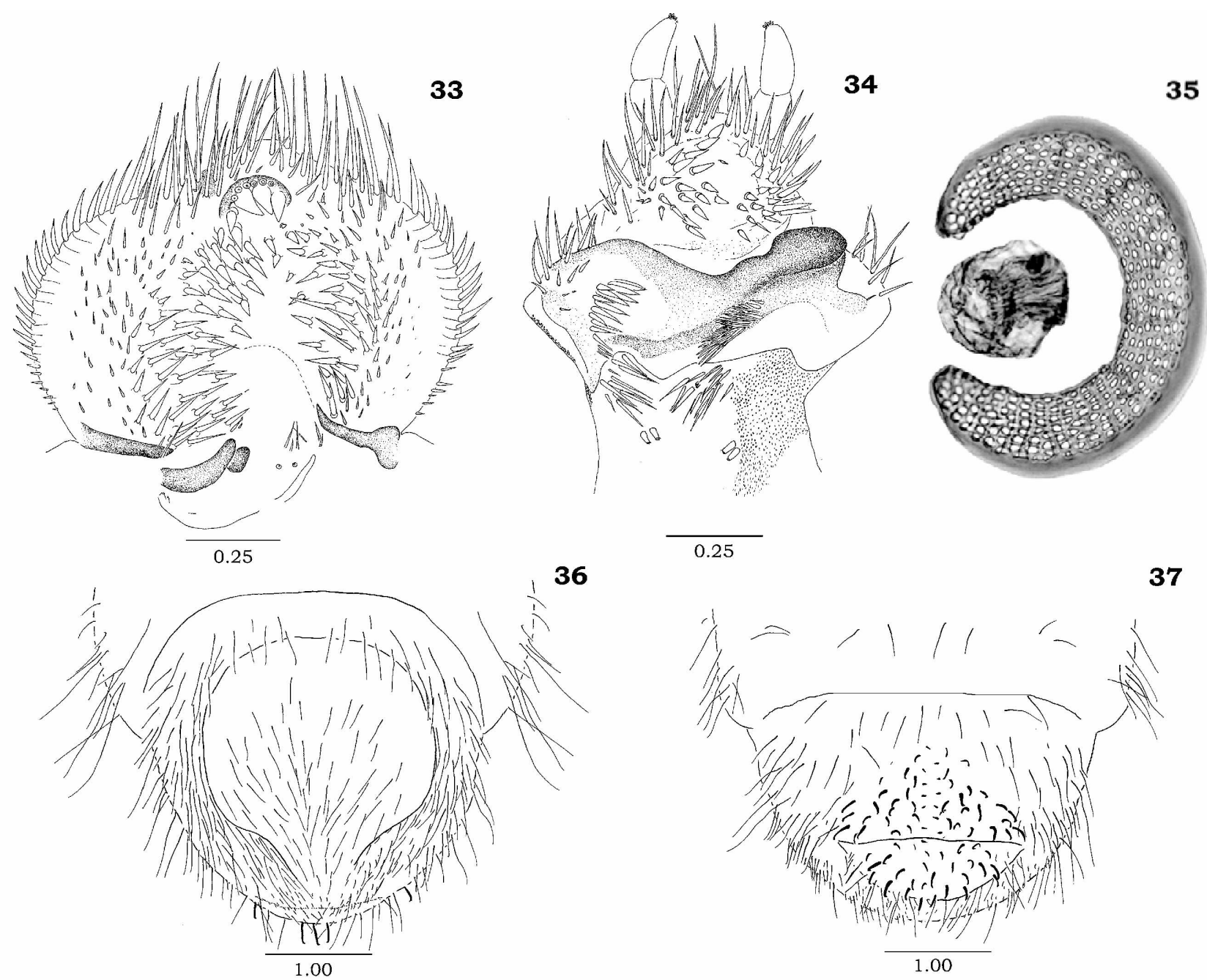

Figs 33-37: Anisoplia remota third-instar larva. 33 - epipharynx; 34 - hypopharynx; 35 - prothoracic spiracle; 36 - dorsum of last abdominal segment; 37 - venter of last abdominal segment.

\section{Key to the known larvae of Anisopliini}

Diagnostic characters of Chaetopteroplia segetum, Anisoplia austriaca, and Anisoplia deserticola are those of Medvedev $(1949,1952)$. Diagnostic characters of Brancoplia leucaspis and Anisoplia farraria are those of Medvedev (1952). Diagnostic characters of Anisoplia lata and Anisoplia agricola are those of Zacharieva-Stoilova (1962), Giljarov (1964), Paşol (1967), and Klausnitzer \& Krell (1997). The description of Anisoplia farraria (Medvedev, 1952) was too incomplete for including this species in the revised key.

1. Palidium present. $\ldots \ldots \ldots \ldots \ldots \ldots \ldots \ldots \ldots, 2$

1'. Palidium absent. . ..................... 9

2. Subcircular furrow on the dorsum of last abdominal segment square. ........... Chaetopteroplia segetum (Herbst).

2'. Subcircular furrow on the dorsum of last abdominal segment round. $\ldots \ldots \ldots \ldots \ldots \ldots \ldots \ldots \ldots \ldots$

3. Third antennal segment as long as the second segment. .... ..................... Anisoplia lata Erichson

3'. Third antennal segment shorter than the second segment. . 4

4. Area defined by the subcircular furrow on dorsum of last abdominal segment (SFA) large (more than $70 \%$ of dorsum of last abdominal segment). Palidium with 6 pali per row. . ................ Brancoplia leucaspis (Castelnau).
4'. SFA small (between $40-50 \%$ of dorsum of last abdominal segment). Palidium with more than 7 pali per row, rarely 6 .

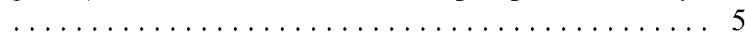

5. SFA uniformly setose. ...... Anisoplia austriaca (Herbst).

5' $S F A$ bare of setae at least on basal margin (Figs 24, 36) . 6

6. SFA with the central longitudinal area hairless. ...... 7

6'. SFA central area setose (cf. Anisoplia agricola Poda)* . 8

7. $S F A$ almost spherical. Distance between the base of the segment and the geometric center of the $S F A$ equal to the distance between this point and the base of the segment. .... Anisoplia alazanica Zaitzev.

7'. SFA more flattened. Distance between the apex of the segment and the geometric center of the SFA 1.5 times the distance between this point and the base of the segment. ..... $\ldots \ldots \ldots \ldots \ldots$ Anisoplia deserticola Fischer.

8. Stridulatory area of mandible with an inter-ridge area 2.1 times the ridge width (Fig. 18). Maxillary articulating area with a row of 8-13 (9) setae just parallel to stridulatory teeth (Fig. 20b). ............. Anisoplia baetica Erichson.

8'. Stridulatory area of mandible with an inter-ridge area 4 times the ridge width (Fig. 31). Maxillary articulating area with a row of 11-23 (16) setae just parallel to stridulatory teeth (Fig. 29b). . . . . . . . . . . Anisoplia remota Reitter. 

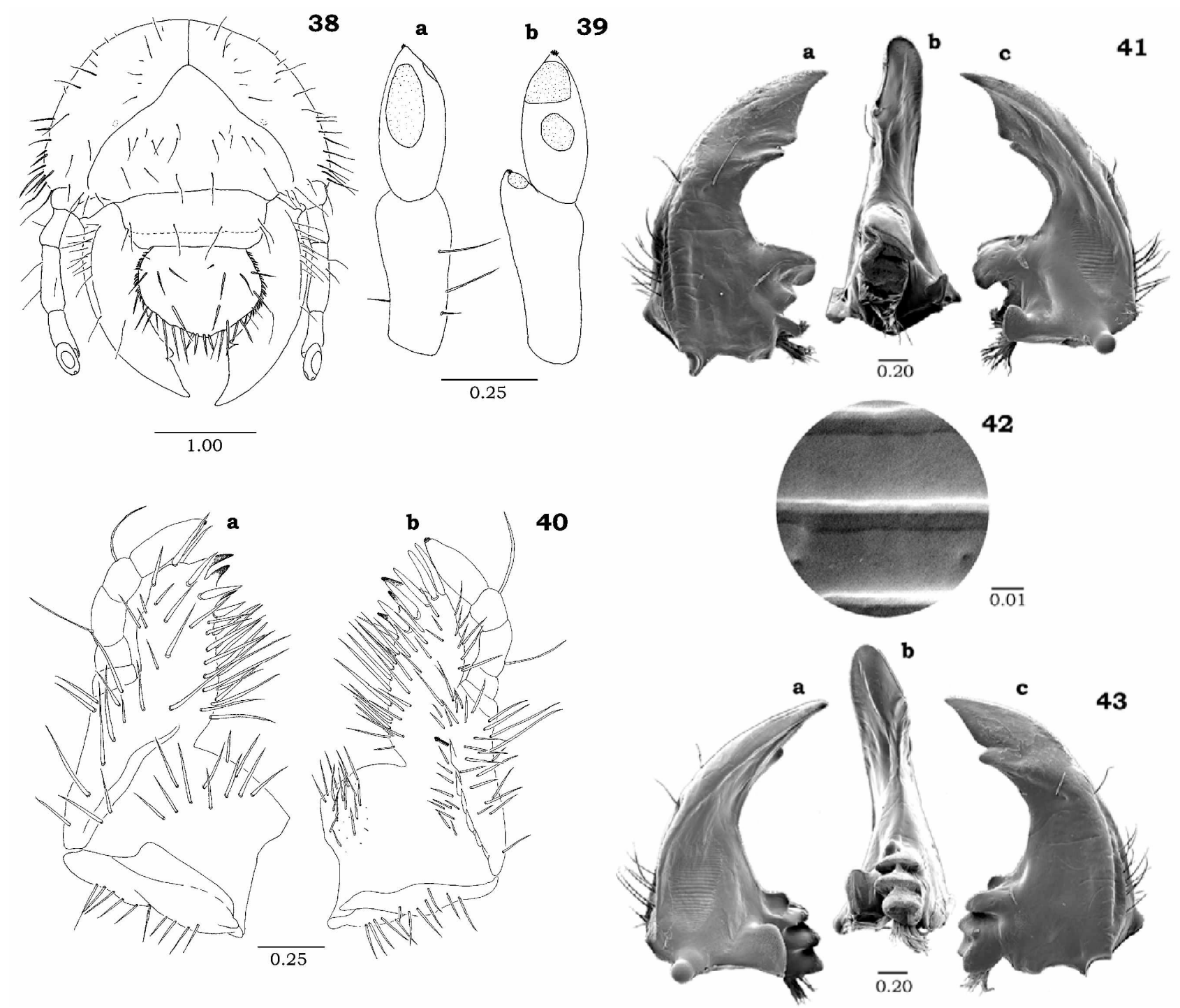

Figs 38-43: Anisoplia depressa third-instar larva. 38 - frontal view of head; 39 - dorsal (a) and ventral (b) view of apical antennal segment showing sensory spots; 40 - ventral (a) and dorsal (b) view of maxilla; 41 - dorsal view (a), lateral view (b), and ventral view (c) of left mandible; 42 - stridulatory area of mandible; 43 - dorsal view (a), lateral view (b) and ventral view (c) of right mandible.

9. Lobes of the prothoracic spiracle equal in size (Fig. 46) Stridulatory area of mandible with an inter-ridge area 2.5 times the ridge width (Fig. 42). . .... Anisoplia depressa Erichson.

9'. Inferior lobe of the prothoracic spiracle conspicuously larger than superior lobe (Fig. 13). Stridulatory area of mandible with an inter-ridge area 1.6 times the ridge width (Fig. 5).

$\ldots \ldots \ldots \ldots \ldots$ Anthoplia floricola (Fabricius).

(*)With the characters of Anisoplia agricola in the literature, further differentiation is impossible.

\section{DISCUSSION}

Until now, the larval characteristic defining Anomalinae was the possession of a raster consisting of 2 monostichious palidia (Ritcher, 1966). However, the absence of a palidium in $A$. depressa and Anthoplia, refutes this assertion. Larvae of Anisopliini can be distinguished from other Anomalinae by the abdominal spiracles: those on I and VIII are conspicuously smaller in Anisopliini larvae. In contrast, in other Anomalinae the spiracles on abdominal segments VII-VIII are similar in size and conspicuously larger than the spiracles on I-VI (Ritcher, 1966). Of the characters used in the diagnosis of species of Anisopliini, we favour those found on the last abdominal segment and the stridulatory area of mandibles. The shape of the stridulatory area on the mandibles and the number of ridges are normally cited in descriptions of larvae (Vanin \& Costa, 1980; Jameson et al., 1994), however, the width of the ridges and the width of the inter-ridge area are not normally described. In the Anisopliini larvae studied, this is a species specific diagnostic character, which may be related to intraspecific communication between larvae. In other Anomalinae, the other mouthparts, such as epipharynx and hypopharynx, are morphologically uniform, probably because of their similar feeding habits. The shape and vestiture of the $S F A$ 

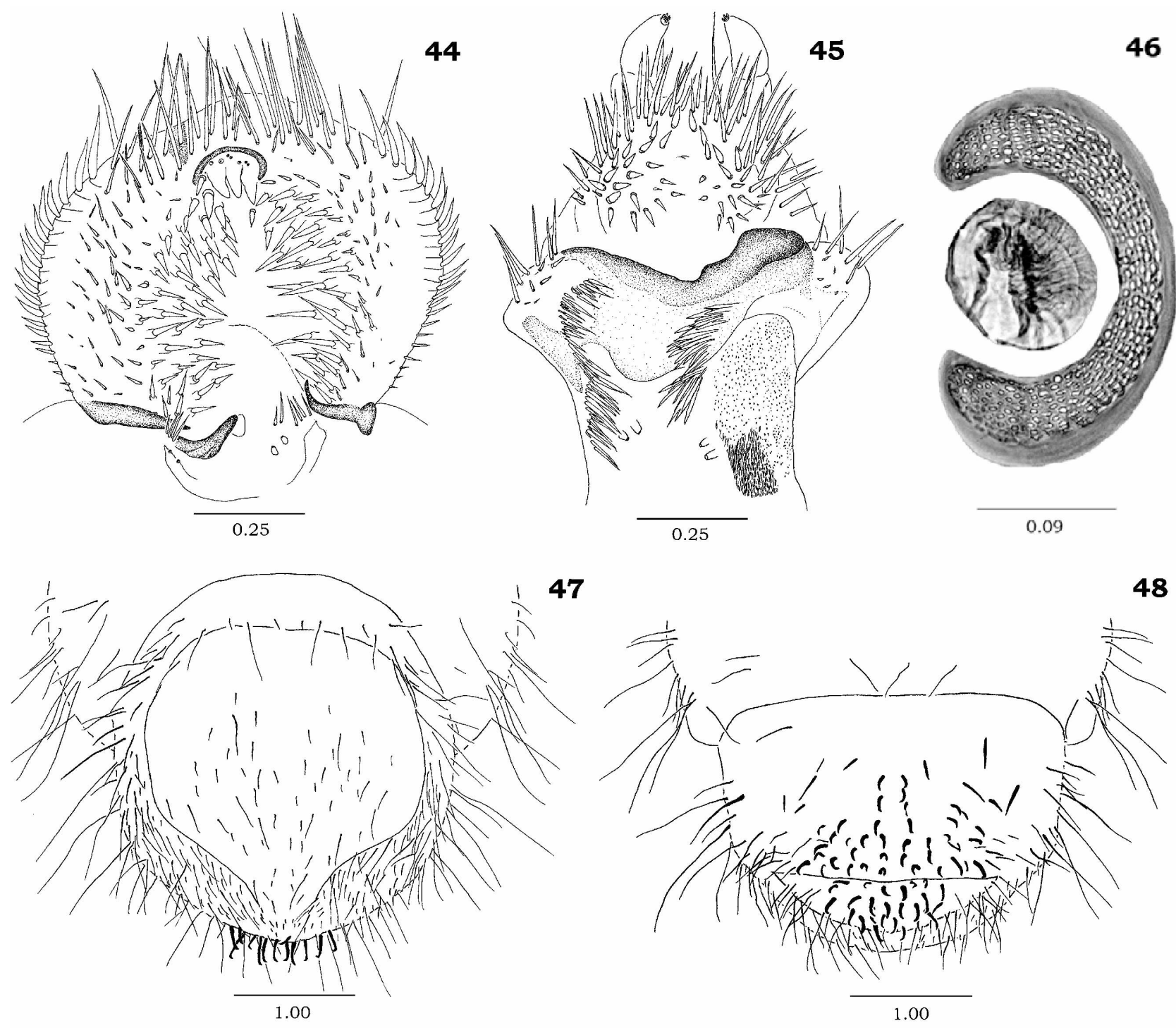

Figs 44-48: Anisoplia depressa third-instar larva. 44 - epipharynx; 45 - hypopharynx. 46 - prothoracic spiracle; 47 - dorsum of last abdominal segment; 48 - venter of last abdominal segment.

are very useful species specific characters and the size and shape of the SFA allows the separation of Chaetopteroplia and Brancoplia from other genera. In contrast, it is difficult to separate the genus Anthoplia from Anisoplia morphologically. In fact, only a few specific characters distinguish Anthoplia from Anisoplia depressa. Our results indicate it is not possible to separate Anthoplia from Anisoplia on the basis of larval morphology. However, more Anisopliini larval descriptions are needed before the phylogenetical trends in the group and the systematic position of the monospecific genus Anthoplia can be determined.

ACKNOWLEDGEMENTS. We thank F.T. Krell whose review greatly improved this manuscript. Kate Burke checked an early English version. The research was supported in part by the Spanish D. G. I. C. Y. T. programme PB95-0235 and by B052000-0148.

\section{REFERENCES}

Baraud J. 1986: Nouvelle classification proposée pour les espéces du genre Anisoplia Fischer, 1824 (Col.: Scarabaeoidea: Rutelidae). Entomologiste 42: 325-344.

Baraud J. 1992: Coléoptères Scarabaeoidea d'Europe. Faune de France et Régions Limitrophes 78 . Fédération française des Sociétés de Sciences naturelles et Société linnéenne de Lyon. Lyon, 850pp.+ 11 plates.

BogacheV A.V. 1946: The grain beetles and their importance for agriculture of Azerbaidzhan. Trudy Inst. Zool. Akademii Nauk Azerb. SSR 11: 74-91 (in Russian).

CARNE P.B. 1951: Preservation techniques for scarabaeid and other insect larvae. Proc. Linn. Soc. N. S. W. 76: 26-30.

EdMONDS W.D. \& Halffter G. 1978: Taxonomic review of immature dung beetles of the subfamily Scarabaeinae (Coleoptera: Scarabaeidae). Syst. Entomol. 3: 307-331.

GiLjAROV M.S. 1964: Family Scarabaeidae. Lamellicornia. In Giljarov M. S. (ed.): Key to Soil Inhabiting Larvae of Insects. Nauka, Moskva, pp. 289-330 (in Russian).

JAMESON M.L., RATClifFe B. \& Morón M.A. 1994: A synopsis of the Neotropical genus Calomacrapsis Bates with a key to 
larvae of the American genera of Rutelini (Coleoptera: Scarabaeidae: Rutelinae). Ann. Entomol. Soc. Am. 87: 43-58.

Klausnitzer B.D. \& Krell F.-T. 1997: 6. Überfamilie: Scarabaeoidea. In Klausnitzer B. (ed.): Die Larven der Käfer Mitteleuropas. 3. Band. Polyphaga Teil 2. Gustav Fischer Verlag, Jena, pp. 11-89.

MachatschKe J.W. 1961: Revision des Genus Anisoplia Serville (1825). Beiträge zur Entomologie 11: 613-655.

Medvedev S.I. 1949: Fauna SSSR, Coleoptera. Vol. X, 3, Scarabaeidae Rutelinae. Izdatel'stvo Akademii Nauk USSR, Moskva, Leningrad, 371 pp. (in Russian).

MEDVEDEv S.I. 1952: Larvae of Lamellicornia of the Fauna of the USSR 47. Akad. Nauk SSSR, Moskva, Leningrad, 344 pp. (in Russian).

PAşol P. 1967: Contributii la studiul morfologiei carabuseilor cerealeor (Anisoplia sp). [Contribution to the morphological study of the grain beetle (Anisoplia sp.)] Lucr. Stiint. Inst. agron. Nicolae Balescu (Ser. A) 10: 603-622 (in Romanian).

Ritcher P.O. 1966: White Grubs and their Allies. Oregon State University Press, Oregon, $219 \mathrm{pp}$.

VANIN S.A. \& Costa C. 1980: Larvae of Neotropical Coleoptera. III: Scarabaeidae, Rutelinae. Papeis Avulsos Zool. 33: $275-282$.

Verdú J.R., Lumaret J.P. \& Galante E. 1998: Description de la larve de Bolbelasmus bocchus (Erichson) et position systématique du genre (Coleoptera: Geotrupidae: Bolboceratinae). Ann. Soc. Entomol. Fr. 34: 245-251.

ZACHARIEVA-STOILOVA B. 1962: Faunistic-biological observations on species of genus Anisoplia Fischer (Scarabaeidae, Rutelinae) in Bulgaria. Izv. Zool. Inst. Sofia 11: 59-115 (in Bulgarian).

Received June 9, 2000; revised March 21, 2001; accepted June 5, 2001 